\title{
A medida provisória 936/2020 e a mediação coletiva aos trabalhadores idosos aposentados
}

\author{
Provisional measure $936 / 2020$ and collective mediation \\ to retired elderly workers
}

\section{Medida provisional 936/2020 y mediación colectiva a los trabajadores mayores jubilados}

Leda Maria Messias da Silva UniCesumar

1

iD) Leticia Mayumi Almeida Takeshita UniCesumar

Resumo: O trabalho visa à análise dos efeitos da medida provisória 936/2020 nas relações trabalhistas que envolvam trabalhadores idosos aposentados no contexto da pandemia de COVID-19. Mediante o método hipotético dedutivo, examina-se a mediação coletiva como meio de concretização da dignidade humana e dos direitos da personalidade em resposta às adversidades previstas na medida provisória. Frisa-se a vulnerabilidade dos idosos e o fato de estes não terem sido devidamente contemplados pelas medidas de socorro emergencial. Aborda-se o direito de personalidade de envelhecer com dignidade e a (re)inserção do idoso no mercado de trabalho. Enfocam-se os óbices à participação dos sindicatos em negociações relativas à medida 936. São descritos os meios 
adequados de resolução de conflitos. Acentua-se a relevância da mediação coletiva como instrumento de composição de conflitos laborais associados com os trabalhadores idosos aposentados durante a pandemia.

Palavras-chave: Medida provisória 936/2020. Trabalhadores idosos aposentados. Mediação coletiva. Direitos da Personalidade.

Abstract: The work aims to analyze the effects of provisional measure $936 / 2020$ on labour relations including retired elderly workers in the context of COVID-19 pandemic. Within hypothetical deductive method, it examines collective mediation as a means of concretion of human dignity and personality rights in response to the adversities situated in the provisional measure. It underlines the vulnerability of the elderly and the fact that they were not effectively contemplated on emergency relief measures. It addres-

2

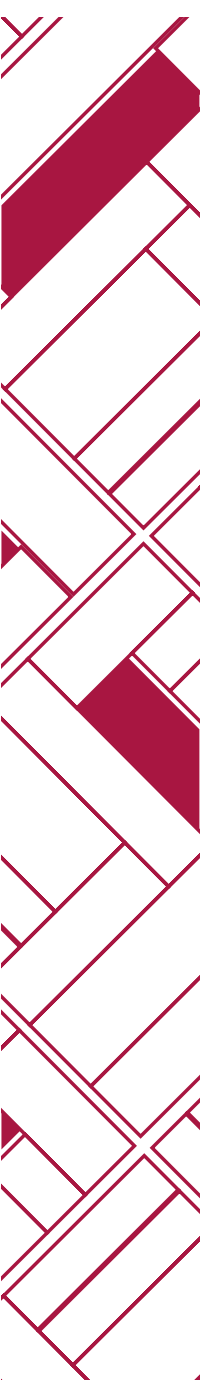
ses the personality right to age with dignity and the (re)insertion of the elderly in the labor market. It focuses on the obstacles to the unions take part in negotiations with regard to 936 measure. It describes the adequate means of conflict resolution. It underlines the relevance of collective mediation as an instrument of labor conflict composition associated with retired elderly workers during the pandemic.

Keywords: Provisional measure 936/2020. Retired elderly workers. Collective mediation. Personality rights.

Resumen: El trabajo analiza los efectos de la medida provisional 936/2020 en las relaciones laborales con trabajadores mayores jubilados en la pandemia COVID-19. Mediante el método deductivo hipotético, se examina la mediación colectiva para la realización de la dignidad humana y los derechos de la personalidad en respuesta a las adversidades previstas en la medida provisional. Hace inca- 
A medida provisória 936/2020 e a mediação coletiva aos trabalhadores idosos...

Leda Maria Messias da Silva • Leticia Mayumi Almeida Takeshita

\section{Introdução}

Nas últimas décadas verificou-se o aumento do número de idosos no Brasil, em face da redução da taxa de fecundidade e pela maior longevidade, propiciada pelo desenvolvimento de ordem científica e tecnológica.

$\mathrm{Na}$ contemporaneidade, a sociedade demarcada pelo consumismo e capitalismo depara-se, mais uma vez, com o embate entre capital e trabalho, realçado no contexto da pandemia do coronavírus, e agravado pela condição de ser o Brasil país em desenvolvimento.

É forçoso constatar que a necessidade de atingir o equilíbrio nas relações entre trabalhador e empregador ganha contornos de complexidade em se tratando de trabalhador de idade avançada. É que este tem de suportar o "ageism", que designa as condutas impregnadas de preconceito e discriminação ao idoso, podendo culminar em marginalização ou até exclusão social.

Com o advento da pandemia e da consequente decretação do estado de calamidade pública no país, surgiu um microssistema jurídico emergencial, com a publicação de inúmeras medidas provisórias, dentre as quais a 936, que suscitou polêmica, ao permitir a suspensão temporária dos contratos de trabalho e a redução proporcional da jornada e salário, sem a intermediação de sindicatos.

Nesse contexto, sob o argumento da situação atípica enfrentada em nível mundial, direitos trabalhistas são "flexibilizados", observando-se linha tênue com a ideia de precarização, notadamente quanto aos trabalhadores aposentados, mas que continuam laborando, que em grande parte, são de idade avançada.

Surgem, naturalmente conflitos, evocando-se técnicas para solução, dentre os quais os meios adequados de resolução, desta- 
A medida provisória 936/2020 e a mediação coletiva aos trabalhadores idosos...

Leda Maria Messias da Silva • Leticia Mayumi Almeida Takeshita

cados em especial pela Lei n. 13.467, de 2017, Reforma Trabalhista. São meios complementares à jurisdição, dentre os quais está a mediação, meio autocompositivo de controvérsias.

Ainda, nessa conjuntura de pandemia, são estimulados e evidenciados os acordos individuais, a mediação e a conciliação como via de resolução de conflitos trabalhistas, notadamente em decorrência da celeridade que o momento exige, porém, não raramente servem de pretexto para a precarização.

O idoso, que geralmente, encontra-se em maior vulnerabilidade, por pertencer ao grupo de risco e não ter sido contemplado, devidamente, nas medidas de socorro emergencial, pode sofrer lesões graves aos direitos da personalidade. Exemplo disso consta do art. $6^{\circ}, \S 2^{\circ}, 11$, a, da medida provisória 936/2020, que vedou o recebimento do benefício emergencial de preservação do emprego e da renda ao empregado em gozo de benefício de prestação continuada do Regime Geral de Previdência Social ou dos Regimes Próprios de Previdência Social, situação em que se enquadra o trabalhador aposentado, geralmente idoso.

Destarte, para a abordagem do tema, o presente artigo inicia-se com a análise do envelhecimento como direito personalíssimo, consoante o Estatuto do Idoso. Conceitua-se a pessoa idosa, notadamente quanto à sua (re)inserção no mercado de trabalho.

Explana-se a medida provisória 936/2020, que ao trazer à baila mecanismos de enfrentamento à pandemia, permitiu o acordo individual entre empregado e empregador, sem a intermediação dos sindicatos.

São tratados os meios adequados de resolução de conflitos, e especificamente a mediação coletiva, de modo a se perfectibilizar a dignidade humana e direitos da personalidade dos idosos diante da medida provisória em apreço. 


\title{
O envelhecimento como direito personalíssimo
}

A tutela jurídica específica da pessoa idosa, no Brasil, iniciou-se a passos lentos, tendo em vista que entre a promulgação da Constituição Federal de 1988, que consagrou em seu art. 230 o dever da família, Estado e sociedade em amparar os anciãos, e o surgimento do Estatuto do Idoso (Lei federal n. 10741/2003) decorreu lapso temporal de quinze anos.

Em seu artigo $8^{\circ}$ consta que o envelhecimento foi alçado à categoria de direito personalíssimo, sendo sua proteção um direito social. Logo, visualiza-se o envelhecimento como direito da personalidade, conquistado aos sessenta anos de idade pelo indivíduo, nos termos do art. $1^{\circ}$, que deve ser respeitado pelo Estado, haja vista sua conotação de direito social.

O envelhecimento é direito subjetivo, por ser ínsito à personalidade do indivíduo, sendo derivado do princípio da dignidade da pessoa humana, consubstanciado no inciso III do $\operatorname{art}^{\circ} 1^{\circ} \mathrm{da}$ Constituição Federal.

É da dignidade humana que provém a necessidade da tutela dos direitos dos anciãos, de modo a se perfectibilizar as igualdades formal e material, como ilustra Piovesan (2017, p. 367):

\begin{abstract}
A garantia da igualdade, da diferença e do reconhecimento de identidades é condição e pressuposto para o direito à autodeterminação, bem como para o direito ao pleno desenvolvimento das potencialidades humanas, transitando-se da igualdade abstrata e geral para um conceito plural de dignidades concretas.
\end{abstract}

O direito ao envelhecimento é oponível erga omnes, por demandar dever geral de abstenção, a fim de proporcionar seu res- 
A medida provisória 936/2020 e a mediação coletiva aos trabalhadores idosos...

Leda Maria Messias da Silva • Leticia Mayumi Almeida Takeshita

peito. Aliás, por inserir-se entre os direitos da personalidade, é pressuposto para a realização dos demais direitos. A pessoa é sujeito de direito, possuindo como faculdades jurídicas elementos da pessoa, voltados à sua proteção.

Seu exercício deve ser livre, possibilitando a autodeterminação nas escolhas existenciais, permeada pela autonomia. É, pois, envelhecer com dignidade, característica a que é conferida evidência hodiernamente com a pandemia.

Percebe-se, todavia, que ao mesmo tempo em que a crise desencadeada pelo vírus é oportunidade para reconhecer nos anciãos seres humanos dignos de respeito, constitui abertura para a intensificação do preconceito e discriminação às pessoas de idade longeva, notadamente no campo do trabalho, o que será analisado a seguir.

\section{A pessoa idosa e sua (re)inserção nas relações de trabalho}

Anteriormente à vinculação com o meio ambiente laboral, cumpre delinear o conceito de pessoa idosa, que pode ser visto sob diversas óticas, tais quais, a biológica, socioeconômica, cultural e jurídica.

O ancião é constantemente compreendido como o indivíduo que em razão do avanço da idade geralmente experimenta declínio nas capacidades física, mental e social. Nesse aspecto, ressalta-se a heterogeneidade, inobservada mormente nos estereótipos conferidos aos idosos, ora como frágeis e incapacitados, ora como independentes e ativos.

Quanto ao ordenamento jurídico pátrio, aponta-se o art. $1^{\circ}$ do Estatuto do Idoso, que dispõe ser a pessoa com sessenta ou mais 
A medida provisória 936/2020 e a mediação coletiva aos trabalhadores idosos... Leda Maria Messias da Silva • Leticia Mayumi Almeida Takeshita

anos de idade. Compõe grupo vulnerável, pois em razão da idade é mais suscetível a ser acometido de doenças e vítima de violência.

É forçoso constatar que referido grupo é reiteradamente estigmatizado, sendo-lhe imputado a responsabilidade por ser opressivo encargo no sistema previdenciário. São considerados "casos perdidos", sobretudo em época de pandemia, estando obsoletos em sua sabedoria, em descompasso com a sociedade consumerista, tecnológica e globalizada da atualidade.

Antes, porém, de aludir à inserção do idoso no mercado de trabalho, cabe pontuar as causas dessa postura. Trata-se de mudança de paradigma no meio social, dada a transição de famílias extensas à tendência de redução do número de seus membros, optando-se pela modalidade nuclear.

O idoso, que normalmente era cuidado por alguma mulher de sua família, tal como filha ou nora, hodiernamente assiste à inserção dessa figura feminina no mercado de trabalho.

É, ainda, cada vez mais observável a situação em que a pessoa idosa é arrimo de família, sendo sua aposentadoria determinante para o sustento e subsistência de seus componentes.

É crucial mencionar a pesquisa "Onde estão os idosos? Conhecimento contra a Covid-19", desenvolvida no âmbito do Centro de Políticas Sociais da Fundação Getúlio Vargas, que dentre outros dados concluiu que os anciãos auferem $59,64 \%$ das aposentadorias da Previdência Social, 40,78\% dos benefícios de Prestação Continuada e $0,89 \%$ do Bolsa Família (FGV Social, 2020).

Nessa conjuntura, inobstante o benefício previdenciário, há o comprometimento da renda com medicamentos e plano de saúde, razão pela qual o idoso vê-se compelido a retornar ao trabalho. E nesse retorno se depara com a realidade acerca do tratamento aos idosos, conforme assevera Beauvoir (2018, p. 239): 
A medida provisória 936/2020 e a mediação coletiva aos trabalhadores idosos... Leda Maria Messias da Silva • Leticia Mayumi Almeida Takeshita

art. $7^{\circ}, X X X$, em que se proíbe a diferença de salários, de exercício de funções e de critério de admissão por motivo de sexo, idade, cor ou estado civil.

Igualmente, verifica-se no art. $1^{\circ}$ da Lei nº 9.029/1995 a proibição de adoção de qualquer prática discriminatória e limitativa para efeito de acesso à relação de trabalho, ou de sua manutenção, dentre outros motivos, a idade.

Face a esse contexto, emerge-se a consideração pelos meios adequados de resolução de conflitos, dentre os quais, a mediação e a conciliação, com fulcro na concretização do princípio da dignidade humana.

\section{A medida provisória 936/2020 como mecanismo de enfrentamento à pandemia de Covid-19 e os óbices à participação dos sindicatos}

É de sabença cursiva que entre 2019 e 2020, primeiramente em Wuhan, na China, surgiu o coronavírus (COVID-19), que rapidamente se alastrou globalmente, desencadeando a pandemia e crises em diversos setores da sociedade.

O vírus, que primariamente afeta o sistema respiratório, tem letalidade ampliada em idosos e portadores de doenças crônicas, razão pela qual se afirma que as pessoas nestas condições compõem grupo de risco.

No Brasil, criou-se um microssistema jurídico de enfrentamento à pandemia. Assim, salienta-se a Lei $n^{\circ} 13.979$, de 2020, que disciplinou as medidas que poderiam ser adotadas na situação de emergência em saúde pública de importância internacional oriunda do coronavírus, bem como o posterior decreto legislativo $n^{\circ} 6$, de 2020. 
A medida provisória 936/2020 e a mediação coletiva aos trabalhadores idosos...

Leda Maria Messias da Silva • Leticia Mayumi Almeida Takeshita

No âmbito laboral, destaca-se a medida provisória n 936, de $1^{\circ}$ de abril de 2020, que instituiu o Programa Emergencial de Manutenção do Emprego e da Renda, objetivando reduzir os impactos sociais causados pela pandemia.

Em suma, apresenta mecanismos voltados ao período da pandemia: o pagamento do benefício emergencial, nos casos de suspensão temporária do contrato de trabalho e de redução proporcional da jornada de trabalho e de salário, podendo ser efetuados mediante acordo individual escrito entre empregado e empregador.

O excerto abaixo, embora relativo à medida provisória $n$. 927/2020, aplica-se à medida 936/2020. Assim, nas palavras de Souza Júnior, Gaspar, Coelho e Miziara (2020, p. 10):

11

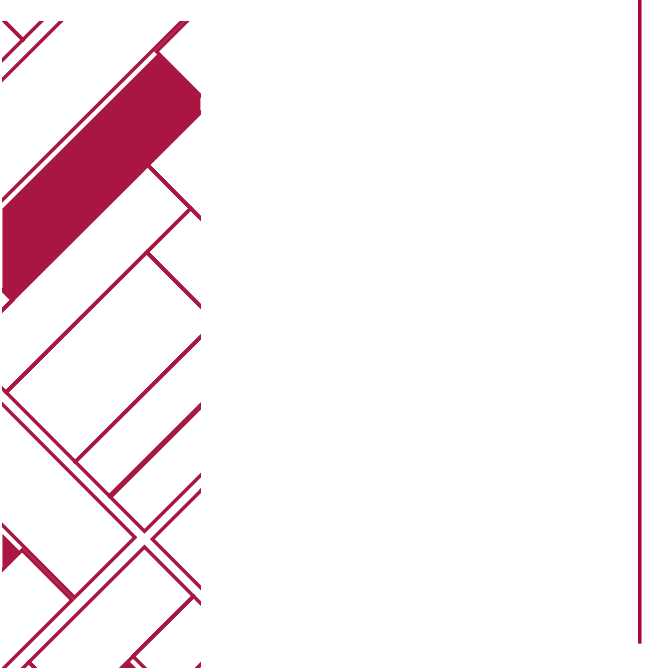

O que mais se enxerga na medida provisória é a ideia socialmente perversa de prevalência da vontade dos empregados e empregadores sobre a lei e os pactos coletivos. Ou seja, considerando a total falta de equilíbrio nas relações de emprego, equilíbrio mais fragilizado ainda em épocas de terror social pelo medo da pandemia, a conta da Covid-19, no mundo do trabalho, será paga pelas vítimas mais vulneráveis diante da escolha de Sofia entre aceitar permanecer empregado em condições precarizantes e perder o emprego e receber algo para a subsistência imediata (se não se tratar de empregador com seus recursos em frangalhos).

Em razão disso, formou-se celeuma entre diversas instituições no sentido de se verificar prejuízo aos trabalhadores, que além de sujeitarem-se à perda salarial, fá-lo-iam mediante acordo individual com o empregador, sendo desnecessário, portanto, a intervenção das entidades sindicais. 
A medida provisória 936/2020 e a mediação coletiva aos trabalhadores idosos...

Leda Maria Messias da Silva • Leticia Mayumi Almeida Takeshita

É que se denota o indubitável descumprimento do art. $7^{\circ}$, inc. XIII, do texto constitucional, relativo à vedação da redução do salário e jornada, a menos que tal constasse de convenção ou acordo coletivo.

Para solucionar esse imbróglio, o partido Rede Sustentabilidade ajuizou a Ação Direta de Inconstitucionalidade nº 6363, com pedido de medida cautelar, aduzindo a impossibilidade de redução de salário e suspensão de contrato de trabalho por acordo individual, posto que incompatíveis com os arts. $7^{\circ}$, VI, XIII e XXVI, e $8^{\circ}$, III e VI da Carta Magna.

Inobstante o Relator Ministro Ricardo Lewandowski, inicialmente tenha deferido em parte a medida cautelar, alegando a necessidade de comunicação ao sindicato a respeito dos acordos individuais, o plenário do Supremo Tribunal Federal manteve a constitucionalidade da medida provisória, concluindo pela dispensa de anuência por parte dos sindicatos.

Salienta-se, porém, que o retrocesso social representado por deixar as entidades sindicais à margem não é recente, haja vista a própria Reforma Trabalhista, que entre outras disposições, extinguiu a contribuição sindical obrigatória, sem alterar o modelo sindical brasileiro, que já não favorecia os sindicatos e continua a desfavorecer, ao permitir a aplicação do direito negociado mesmo aos não associados.

Trata-se de medida nociva, que ignora a autonomia coletiva e negocial de que detém o sindicato, essencial na defesa dos direitos laborais em tempos de crise. Nas palavras de Borba (2020, p. 557):

E aí, somente o sindicato tem condição de negociar a não flexibilização ou em que medida ela deveria ocorrer, de forma que, utilizando-se dos princípios da transparência, 
A medida provisória 936/2020 e a mediação coletiva aos trabalhadores idosos...

Leda Maria Messias da Silva • Leticia Mayumi Almeida Takeshita

razoabilidade e boa-fé, as condições de trabalho, in concreto, seriam equacionadas da melhor forma tanto para o trabalhador quanto para a empresa.

À redução de salário exsurge ainda maior inquietude, haja vista a natureza alimentar do salário, que resta prejudicado na atual conjuntura. Logo, fere frontalmente a dignidade humana em seu mínimo existencial.

Outro ponto consta do art. $6^{\circ}, \S 2^{\circ}, 11$, alíneas "a" a "c", da MP 936/2020, atinente à vedação da concessão do benefício emergencial a determinados empregados, dentre os quais o que esteja em gozo de benefício de prestação continuada do Regime Geral de Previdência Social ou dos Regimes Próprios de Previdência Social, com a ressalva do parágrafo único do art. 124 da Lei n 8.213/1991.

Nesse cenário, evidencia-se a vulnerabilidade do ancião, vez que consoante análise nas capitais do país, capitaneada em 2018 pela Confederação Nacional de Dirigentes Lojistas e Serviço de Proteção ao Crédito, dentro dos 70\% de idosos aposentados, 21\% continuam trabalhando, tendo como principal razão (47\%) a insuficiência da renda para arcar com as despesas. Esta porcentagem é corroborada pelo fato de aproximadamente $91 \%$ dos idosos contribuírem financeiramente com o orçamento familiar (SPC, 2018).

Destarte, o ancião, ainda que aposentado, face à insuficiência do benefício previdenciário para arcar com seus dispêndios e de sua família, vê-se, de certo modo, compelido a retornar ao mercado de trabalho, haja vista o indubitável comprometimento de sua renda com medicamentos e plano de saúde.

Logo, ao empregado idoso restaria a expectativa pela boa vontade do empregador em conceder-Ihe a ajuda compensatória mensal de que trata o art. $9^{\circ}$ da medida em apreço - isto quando 
A medida provisória 936/2020 e a mediação coletiva aos trabalhadores idosos...

Leda Maria Messias da Silva • Leticia Mayumi Almeida Takeshita

não tiver seu contrato de trabalho rescindido. Aliás, consoante seu dispositivo $\$ 1^{\circ}$, inc. I, referido auxílio terá seu valor pactuado em acordo individual ou negociação coletiva.

Em seguida, publicou-se a portaria n 10.486/2020, da Secretaria Especial de Previdência e Trabalho do Ministério da Economia, disposta a regulamentar a MP 936/2020. No art. 4 ${ }^{\circ}$ §2 dispôs acerca da proibição do entabulamento de acordo individual visando à redução proporcional de jornada de trabalho e de salário ou a suspensão temporária do contrato de trabalho envolvendo empregado enquadrado em alguma das vedações à prestação do benefício emergencial previstas em tal artigo.

Com efeito, é vedado ao idoso aposentado o recebimento do benefício emergencial, e não Ihe é possível realizar acordo individual com o empregador para suspender o contrato de trabalho ou reduzir jornada e salário.

Quais seriam, então, as alternativas plausíveis ao ancião que embora aposentado continua laborando? A priori, a partir de interpretação a contrario sensu, extrai-se a possibilidade de suspensão do contrato de trabalho ou redução de jornada e salário mediante negociação coletiva, isto é, por acordo coletivo ou convenção coletiva de trabalho.

Enquanto o acordo coletivo implica na participação da empresa e do sindicato da categoria profissional, a convenção coletiva envolve os sindicatos patronal e profissional. Aliás, a negociação coletiva pode ser alçada à categoria plena, se incluir a mediação para solução do conflito. Certo é que não se justificaria reduzir salário e jornada do idoso, sem contrapartida, já que ao idoso aposentado não seria pago o benefício emergencial. Diante do impasse, aos sindicatos caberia a solução desta situação de injustiça. 


\title{
Meios adequados de resolução de conflitos no âmbi- to trabalhista
}

Inicialmente, cumpre constar que à jurisdição trabalhista o exercício da conciliação é ínsito, razão pela qual constitui ramo assaz efetivo do Poder Judiciário, consoante os dados seguintes, oriundos do Relatório Justiça em Números de 2019, do Conselho Nacional de Justiça (CNJ) (2019, p. 143):

\begin{abstract}
A Justiça que mais faz conciliação é a Trabalhista, que solucionou $24 \%$ de seus casos por meio de acordo - valor que aumenta para 39\% quando apenas a fase de conhecimento de primeiro grau é considerada. O TRT2 apresentou o maior índice de conciliação do Poder Judiciário, com 31\% de sentenças homologatórias de acordo. Ao considerar apenas a fase de conhecimento do $1^{\circ}$ grau, o maior percentual é verificado no TRT9 com 48\%.
\end{abstract}

Depreende-se o estímulo à autocomposição, por se primar a solução da controvérsia diretamente entre os envolvidos, e, no caso de intervenção, seja esta imparcial, cedendo aos indivíduos o protagonismo no deslinde do impasse. Porém, nas questões trabalhistas, considerando-se que empregado é subordinado e dependente economicamente, um acordo individual seria na realidade um verdadeiro acordo com adesão do empregado.

De um modo geral, a crise que perpassa o Judiciário, representada por morosidade e ineficiência, leva juristas a debruçaram-se em busca de soluções, de forma que a cultura da litigiosidade, arraigada pela tradição brasileira cede espaço à cultura da paz, marcada pelo consenso. 
A medida provisória 936/2020 e a mediação coletiva aos trabalhadores idosos...

Leda Maria Messias da Silva • Leticia Mayumi Almeida Takeshita

Notável é o marco representado pela resolução n. 125, de 2010, do CNJ, que instituiu a Política Judiciária Nacional de tratamento dos conflitos de interesses, tendo como premissa a utilização de meios adequados de resolução de conflitos.

Na seara laboral, a resolução n. 174, de 2016, do Conselho Superior da Justiça do Trabalho (CSJT), que instituiu a implantação dos Núcleos Permanentes de Métodos Consensuais de Solução de Disputas pelos Tribunais Regionais do Trabalho, aos quais coube a realização de mediação e conciliação em sua competência, além da homologação dos acordos entabulados.

Nessa linha, cotejando a Justiça comum com a obreira, consignam Grosman e Bayer (2019, p. 407-408):

Da mesma maneira, paralela à da Justiça comum, na Justiça do Trabalho estabeleceu-se criar centros de conciliação, a exemplos dos CEJUSCS, com a diferença, contudo, de que somente servidores ativos e inativos da Justiça do TrabaIho, assim como magistrados aposentados, podem exercer a função de conciliadores e mediadores.

Neste diapasão, a Reforma Trabalhista instaurou o processo de jurisdição voluntária para homologação de acordo extrajudicial, que ganhou capítulo próprio na Consolidação das Leis do Trabalho (CLT), nos artigos 855-B a 855-E. Para Gentile (2018, p. 251):

A Lei n. 13.467/2017, conhecida como Reforma Trabalhista, vem para retirar o receio de se estabelecer acordos extrajudiciais trabalhistas. Talvez, não pelos motivos devidos, esses acordos tendem a ganhar mais força nos próximos meses já que as recentes modificações legislativas torna- 
ram mais arriscados os ajuizamentos de demandas, o que provavelmente incentivará a busca por outras vias de solução de conflitos que não o Judiciário.

Regulamentou-se, pois, o processo de homologação de acordos realizados fora da Justiça obreira, que se inicia por meio de petição conjunta dos advogados das partes, consoante o caput do art. 855-B, da CLT. Não há lide, tampouco partes, sendo, em verdade, a análise pelo magistrado da validade jurídica do acordo entabulado.

Os meios adequados de solução de controvérsias não são alternativos à via adjudicatória, mas complementares a esta, desenvolvendo-se a ideia da multiplicidade de caminhos aptos à obtenção de justiça, também denominada justiça multiportas. Por isso, prefere-se "adequado" ao caracterizar os meios de resolução de conflitos pautados no consenso.

Quanto a esses meios, frequentes são as hesitações em efetuar a composição sob o argumento de indisponibilidade dos direitos trabalhistas. Porém, é imperativo desmistificar tal indisponibilidade, geralmente suposta quando se refere a normas de ordem pública na seara trabalhista, consoante expõe Tupinambá (2018, p. 55):

\begin{abstract}
As normas chamadas de "ordem pública" ou imperativas, neste contexto, significa dizer apenas que o Direito do Trabalho se volta para a correção de assimetrias, mas não que os direitos sejam indisponíveis! Apenas se uma determinada solução for vedada de forma expressa é que as partes não a poderão ajustar.
\end{abstract}

Ademais, os meios adequados de resolução de conflitos vêm-se consolidando, em especial no âmbito laboral, historicamente conheci- 
A medida provisória 936/2020 e a mediação coletiva aos trabalhadores idosos... Leda Maria Messias da Silva • Leticia Mayumi Almeida Takeshita

do por seu teor conciliatório, no entanto, não se pode descuidar para que não haja desvirtuamentos quando realizadas tais composições.

\section{Mediação coletiva como instrumento de concretiza- ção da dignidade humana e dos direitos da persona- lidade ao trabalhador idoso aposentado frente à MP} n. $936 / 2020$

A mediação constitui meio de solução de controvérsias, no qual a um terceiro imparcial cabe auxiliar os envolvidos no estabelecimento de diálogo, visando ao deslinde do conflito. Em comparação à via adjudicatória, tem como vantagens a redução de dispêndios econômicos e de desgastes emocionais, provocados pela instauração de processo.

Seu marco regulatório é a Lei n. 13.140/2015, Lei de Mediação, que a define, no art. $1^{\circ}$, parágrafo único, como atividade técnica exercida por terceiro imparcial sem poder decisório, que, escolhido ou aceito pelas partes, as auxilia e estimula a identificar ou desenvolver soluções consensuais para a controvérsia.

Em decorrência de sua vedação a sugerir ou impor soluções ao caso concreto, acentua-se o protagonismo dos indivíduos envolvidos no procedimento, que desfrutam de maior segurança jurídica, por serem responsáveis pela resolução de suas controvérsias.

No entanto, consta do parágrafo único de seu art. 42 que as disposições procedimentais previstas na lei em comento não se destinam à aplicação na seara trabalhista, que deverá possuir regulamentação própria.

Todavia, apesar das particularidades da mediação trabalhista, há de se considerar que ao menos a essência do conceito da mediação permanece a mesma. Esclarece Sampaio Júnior (2018, p. 223): 
Nas relações que envolvem conflitos trabalhistas, pela maior peculiaridade da matéria e até mesmo efeitos distintos dos acordos feitos em tal área, além dos limites e possibilidade de revisitação, a lei ora comentada remete o tratamento a lei específica, o que deve ser aplaudida também, contudo ainda nos atrevemos a dizer que alguns princípios previstos no artigo $2^{\circ}$ da lei se aplicam, como por exemplo, o da imparcialidade do mediador, oralidade, busca do consenso e boa-fé, mesmo que a doutrina não aceite de forma unânime tal assertiva.

A adequação da mediação à matéria trabalhista é igualmente verificada em razão daquela ser indicada preferencialmente nos casos em que houver vínculo anterior entre as partes, conforme o art. 165, §3², do Código de Processo Civil. É o que ocorre na seara trabalhista, em que o contrato de trabalho é de trato sucessivo, perdurando a relação jurídica entre empregado e empregador.

Portanto, pela mediação, pode-se enfocar o futuro, visando elidir a rescisão contratual. Isto revela-se crucial, especialmente ao se considerar o trabalhador idoso aposentado, que depende, principalmente financeiramente do emprego para sua subsistência, bem como, se despedido encontrar-se-á em situação complexa para efetivar nova contratação, diante da pandemia.

Convém reforçar a resolução n. 174, de 2016, do CSJT, que, espelhada na resolução n. 125/2010 do CNJ, preceituou no inciso II do art. $1^{\circ}$, do capítulo I, que a mediação é meio alternativo de resolução de conflitos, em que o terceiro imparcial é o magistrado ou servidor público, incumbido de aproximar, empoderar e orientar as partes, não podendo formular sugestões.

A mediação pode ocorrer nas modalidades endo ou extraprocessual. A primeira ocorre no âmbito do processo, quando a lide 
A medida provisória 936/2020 e a mediação coletiva aos trabalhadores idosos...

Leda Maria Messias da Silva • Leticia Mayumi Almeida Takeshita

já está instaurada. Na segunda, a mediação transcorre com vista a impedir a judicialização da controvérsia.

Constitui ferramenta na negociação coletiva plena, propiciando maior efetividade no cumprimento do acordo efetuado entre os participantes, haja vista terem efetivamente envidado esforços almejando o deslinde do impasse.

Quanto à preocupação relativa ao teor protetivo do Direito do Trabalho, enfatiza-se que na mediação coletiva é vislumbrada igualdade jurídica, já que, de um lado, figura-se o sindicato da categoria profissional, e de outro, a empresa e/ou sindicato da categoria econômica.

Nessa linha, pode-se, inclusive, posicionar o membro do Ministério Público do Trabalho (MPT) como mediador, designado para facilitar a comunicação entre os envolvidos. Leite (2017, p. 122) elenca as vantagens nesta mediação coletiva: “a) credibilidade dos Membros oficiantes quanto à sua atuação e formação jurídica; b) isenção e imparcialidade absolutas em seu procedimento; c) ausência de custos para as partes, salvo se houver necessidade de perícias ou produção de outras provas."

A mediação pode se desmembrar em uma ou mais reuniões com os envolvidos, adequando-se às necessidades do conflito no caso concreto. Possibilita soluções que considerem os interesses subjacentes à controvérsia, equilibrando ambos os lados.

Acresça-se a nota técnica conjunta n. 6/2020, da Procuradoria Geral do Trabalho - MPT, por meio da Coordenadoria Nacional de Promoção da Liberdade Sindical, que elenca, no pressuposto XI, a priorização do Parquet aos meios de autocomposição de conflitos, a fim de entabular negociação coletiva e mediação nas questões concernentes à pandemia.

A mediação também pode ser solicitada perante a Secretaria Especial de Previdência e Trabalho do Ministério da Economia, pelos 
A medida provisória 936/2020 e a mediação coletiva aos trabalhadores idosos... Leda Maria Messias da Silva • Leticia Mayumi Almeida Takeshita

sindicatos representantes da categoria dos trabalhadores e empregadores ou diretamente pela empresa. Devido a pandemia, a solicitação em apreço pode ser efetuada digitalmente. O procedimento é realizado por mediador público, sendo gratuito, e a análise da solicitação perfaz um período de aproximadamente trinta dias.

Nesse âmbito, cabe salientar que a Subsecretaria de Relações do Trabalho do Ministério da Economia efetua o registro de instrumentos coletivos de trabalho, por meio do sistema Mediador, via Internet.

Cita-se ainda a Recomendação n. 1/2020, do CSJT, que diante da pandemia, recomendou a mediação e conciliação por meio eletrônico, em conflitos individuais ou coletivos. Portanto, considerando a condição de vulnerabilidade dos idosos aposentados e, até pelo desamparo da medida 936/20, em relação aos mesmos, que não permite auferirem o benefício emergencial, faz-se justo um acordo coletivo realizado com mediação, diante do conflito. Certamente, mais eficazes serão estes acordos coletivos, na busca da garantia dos direitos da personalidade da população de trabalhadores aposentados que, por necessidade, continuaram trabalhando.

\section{Conclusões}

A medida n. 936/2020, ao coibir o pagamento do benefício emergencial ao trabalhador aposentado, presume equivocadamente que este já estaria devidamente guarnecido, ignorando a realidade de uma miríade de brasileiros, que com idade avançada, acabam por retornar ao trabalho para garantir sua subsistência.

A desnecessidade de os sindicatos participarem ou ao menos serem comunicados da pactuação da suspensão temporária de 
A medida provisória 936/2020 e a mediação coletiva aos trabalhadores idosos...

Leda Maria Messias da Silva • Leticia Mayumi Almeida Takeshita

contrato de trabalho e redução de jornada e salário trouxe ainda maiores controvérsias.

Com a portaria n. 10.486/2020 resta claro que as medidas acima não podem ser efetuadas por acordo individual para trabaIhadores aposentados. Revela-se, assim, mais segura a negociação coletiva para dispor acerca de tais direitos, sendo ainda mais benéfico o uso da mediação coletiva como seu instrumento.

Destarte, a negociação coletiva é indispensável ao cenário hodierno, bem como a mediação, resguardando-se a tutela dos direitos trabalhistas, amalgamada à corporificação do princípio da dignidade humana.

A mediação adquire relevância, notadamente pela celeridade que demanda o momento. É mecanismo viável para equacionar os interesses antagônicos nas relações de trabalho, permitindo o diálogo social, em especial na crise sanitária e humanitária que assola a humanidade.

Torna possível a análise pormenorizada dos interesses em questão, não se justificando que medidas como a redução salarial sejam feitas por acordo individual, ferindo-se a dignidade humana, vez que o salário tem natureza alimentar. Ademais, resguardaria os direitos da personalidade dos idosos, garantindo com mais eficácia o mínimo existencial.

É ponto nodal, portanto, a adequação da mediação coletiva aos contratos de trabalho de trabalhadores idosos aposentados, com a defesa de seus interesses pelas entidades sindicais, a fim de propiciar a concretização do princípio da dignidade humana e do direito personalíssimo ao envelhecimento.

Frisa-se que embora o período seja deveras excepcional, não se pode usá-lo como pretexto para o menoscabo dos direitos trabalhistas, mormente de pessoas de idade longeva, que visualizam no trabalho recurso imprescindível à subsistência. 
A medida provisória 936/2020 e a mediação coletiva aos trabalhadores idosos... Leda Maria Messias da Silva • Leticia Mayumi Almeida Takeshita

Espera-se, enfim, que a mediação se consolide como meio de resolução de conflitos com efetividade perante a sociedade, devolvendo notadamente às pessoas idosas esperança diante da crise desencadeada pelo coronavírus.

\section{Referências}

Beauvior, Simone de. A velhice. 2. ed. Tradução de Maria Helena Franco Martins. Rio de Janeiro: Nova Fronteira, 2018.

BOrba, Joselita Nepomuceno. Atuação sindical em tempos de coronavírus. In: O Direito do Trabalho na Crise da COVid-19. Alexandre Agra Belmonte, Luciano Martinez, Ney Maranhão (coords.). Salvador: Editora JusPodivm, 2020, P. 525-562.

23

BRASil. Constituição da República Federativa do Brasil de 1988. DisPONÍVEL EM: HTTP://WWW.PLANALTO.GOV.BR/CCIVIL_03/CONSTITUICAO/CONSTITUICAOCOMPILADO.HTM. ACESSO EM: 08 MAIO 2020.

BRasil. Decreto Legislativo nº 6, de 20 de março de 2020. Disponível EM: HTTP://WWW.PLANALTO.GOV.BR/CCIVIL_03/PORTARIA/DLG6-2020.HTM. ACESSO EM: 04 MAIO 2020.

BRASil. Decreto-Lei N 5.452, de $1^{\circ}$ de maio de 1943. Disponível em: HTTP://WWW.PLANALTO.GOV.BR/CCIVIL_03/DECRETO-LEI/DEL5452.HTM. ACESSO EM: 04 MAIO 2020.

BRASIL. LEI N 9.029, de 13 dE ABRIL dE 1995. DISPONÍVEL EM: HTTP://WWW. PLANALTO.GOV.BR/CCIVIL_03/LeIS/L9029. HTM. ACESSO EM: 06 MAIO 2020.

BRASIL. LeI 10.741, de $1^{\circ}$ de Outubro de 2003. DisponíVEL em: hTtP:// WWW.PLANALTO.GOV.BR/CCIVIL_03/LEIS/2003/L10.741.HTM. ACESSO EM: 11 MAIO 2020. 
A medida provisória 936/2020 e a mediação coletiva aos trabalhadores idosos... Leda Maria Messias da Silva • Leticia Mayumi Almeida Takeshita

BRASIL. Lel 13.105, de 16 de março de 2015. Disponível em: htTP://WwW. PLANALTO.GOV.BR/CCIVIL_03/_ATO2015-2018/2015/LEI/L13105.HTM. ACESSO EM: 10 MAIO 2020.

BRASIL. LeI 13.140, de 26 de JUNho de 2015. Disponível EM: HTTP://WWW. PLANALTO.GOV.BR/CCIVIL_03/_ATO2015-2018/2015/LEI/L13140.HTM. ACESSO EM: 11 MAIO 2020.

BRASIL. LeI 13.979, de 6 de feVereiro de 2020. Disponível eM: hTTP:// WWW.PLANALTO.GOV.BR/CCIVIL_03/_ATO2019-2022/2020/LEI/L13979.HTM. ACESSO EM: 11 MAIO 2020.

BRASIL. Medida provisória 936, de $1^{\circ}$ de Abril de 2020. Disponível EM: HTTP://WWW.PLANALTO.GOV.BR/CCIVIL_03/_ATO2019-2022/2020/MPV/ MPV936. HTM. ACESSO EM: 04 MAIO 2020.

24

BRASil. Ministério da Justiça. Conselho Nacional de Justiça. Resolução 125, de 29 de NOVEMBRo de 2010. DisPoníVEL EM: HTTPS://WWW.CNJ.JUS.BR/ WP-CONTENT/UPLOAdS/2011/02/ResOLUCAO_N_125-GP.PDF. ACESSO EM: 13 MAIO 2020.

BRASIL. STF. Ação Direta de Inconstitucionalidade Nº 6363. DisPONÍVEL EM: HTTP://REDIR.STF.JUS.BR/ESTFVISUALIZADORPUB/JSP/CONSULTARPROCESSOELETRONICo/ConsultarPRocessoEletronico.JSF?SEQObJetoinCIDENTE=5886604. Acesso em: 08 maIO 2020.

CONSElho naCiOnAl dE JuStiçA. Relatório Justiça em Números 2019. BRASÍlIA: CNJ, 2019.

CONSELHO SUPERIOR DA JUSTIÇA DO TRABALHO (BRASIL). Recomendação N. 1/CSJT.GVP, de 25 de março de 2020. DiÁRIo EletrônIco da Justiça do Trabalho: caderno administrativo [Do] Conselho Superior da Justiça do Trabalho, Brasília, DF, N. 2942, P. 3-5, 26 mar. 2020. 
A medida provisória 936/2020 e a mediação coletiva aos trabalhadores idosos...

Leda Maria Messias da Silva • Leticia Mayumi Almeida Takeshita

CONSELHO SUPERIOR DA JUSTIÇA DO TRABALHO (BRASIL). ResOlução N. 174, DE 30 de SETEMBRo de 2016. DisPonível EM: HTTP://WWW. CSJT.JUS.BR/C/DOCUMENT_LIBRARY/GET_FILE?UUID=235E3400-9476-47A0-8BBBBCCACF94FAB4\&GROUPID=955023. ACESSO EM: 08 MAIO 2020.

FGV SoCial - Fundação Getúlio Vargas Social. Pesquisa: onde estão os IDosos? CONHECIMENTO CONTRA O COVID-19. DisPonível EM: hTtPS://WWW. CPS.FGV.BR/CPS/Bd/docs/Pesquisa-Covidage-FGV-Social-MarCelo-NerI.PDF. ACESSO EM: 15 MAIO 2020.

GENTILE, Isabela Reimão. A efetividade do acordo extrajudicial trabalhisTA: INSTRUMENTOS DE SEGURANÇA JURÍDICA AOS ACORDANTES. IN: TUPINAMBÁ, Carolina (COORD.). Soluções de conflitos trabalhistas: novos Caminhos. SÃo PAULO: LTR, 2018.

Grosman, Claudia Frankel; Bayer, Sandra Regina Garcia Olivan. As 25 OPORTUNidades dA APLICAÇÃo da Mediação no ÂMBITO Empresarial. IN: ALMEIDA, TÂnia; PElajo, Samantha; JHONATAN, Eva. Mediação de conflitos: para iniciantes, praticantes e docentes. Salvador: Ed. JusPodivm, 2019. 2. ED., REV., ATUAL. E AMPL.

Leite, Carlos Henrique Bezerra. Ministério Público do Trabalho: doutriNA, JURISPRUdÊNCIA E PRÁtıCA. São PaUlo: Saraiva, 2017.

MiNistéRIO PÚBliCO dO TRABALHO. Nota TÉcnica Conjunta Nº 06/2020 - PGT/CONALIS. DISPONÍVEL EM: HTTPS://ANEC.ORG.BR/WP-CONTENT/UPLOADS/2020/03/MPT-NOTA-TE\%CC\%81 cNICA-N.-6-2020-CONALIS-COVID-19.PdF. ACESSO EM: 14 MAIO 2020.

PiOVeSAN, Flavia. Temas de direitos humanos. 10. ed. ReV., atual. e ampl. São Paulo: Saraiva, 2017.

SAMPAiO JÚNIOR, José Herval. Art. 42. In: CABRAL, Trícia Navarro Xavier; CURY, Cesar Felipe (coords.). Lei de mediação comentada artigo 
A medida provisória 936/2020 e a mediação coletiva aos trabalhadores idosos... Leda Maria Messias da Silva • Leticia Mayumi Almeida Takeshita

Por ARTIgo: dedicado À memória da Prof ${ }^{a}$. Ada Pellegrini Grinover IndaiatuBA, SP: Editora Foco, 2018.

SILVA, Leda Maria Messias; KLOSTER, Jalane Tansin. Idade X dignidade no mercado de trabalho. In: CONPEDI (Org.). Anais XVIII Encontro NacioNAl do Conpedi. Florianópolis: Fundação Boiteux, 2009, p. 600-627. DıSPONÍVEL EM: HTTP://WWW.PUBLICADIREITO.COM.BR/CONPEDI/ANAIS/36/12_1292. PDF. ACESSO EM: 09 MAIO 2020.

SOUZA JÚNIOR, Antonio Umberto de; GASPAR, Danilo Gonçalves; COElho, Fabiano; MiZiara, Raphael. Medida provisória 927/2020 COMENTADA ARTIGO POR ARTIGO: COVID-19 E OS IMPACTOS NA ÁREA TRABALHISta. Revista dos Tribunais, 2020. Disponível em: http://escola.mpu.mp.br/ PUBLICACOES/OBRAS-AVULSAS/ACERVO-COMPARTILHADO/COVID-19-E-OS-IMPACTOSDA-AREA-TRABalhista. Acesso em: 07 maio 2020.

26

SPC BRASIL. Mesmo aposentados, $21 \%$ dos idosos continuam tRaBALHANDO, REVELA PESQUISA CNDL/SPC BRASIL. DisPONÍVEL EM: hTTPS:// WWW.SPCBRASIL.ORG.BR/PESQUISA/5648. ACESSO EM: 08 MAIO 2020.

TUPINAMBÁ, Carolina. Ao SEU disPor! A lendA dA INDISPONIBILIDADE dOS DIREITOS DOS TRABALHADORES. IN: SOluçõES DE CONFLITOS tRABALHISTAS: NOVOS caminhos. TUPinAmBÁ, Carolina (COORd.). São Paulo: LTR, 2018. 